\title{
Research on Fuzzy PD Current Controller for FDWRD
}

\author{
Zebiao Shan ${ }^{1}$, Yaowu Shi ${ }^{1}$, Lanxiang $\mathrm{Zhu}^{*{ }^{2}}$ and Moran $\mathrm{Ju}^{1}$ \\ 1. College of Communication Engineering, Jilin University, \\ Changchun 130022, China \\ 2. Changchun Architecture and Civilengineering College, \\ Changchun 130699, China \\ *Corresponding Author: 519007262@qq.com
}

\begin{abstract}
A fuzzy control scheme is proposed for the system of filling and draining off water of the rubber dam (FDWRD) which is a typical nonlinear, multi-variables, time-varying and strong coupling control system base on traditional PID control or model-based control methods can not meet its constant flow sufficient drainage control requirements, during to it couldn't be established accurate mathematical model. In a practical project, a fuzzy PD controller is designed for the constant current control of filling and draining off water of the rubber dam, combining with the traditional PID algorithm which is widely used in industrial process control, and achieved good control effect. This paper elaborates the control system of filling and draining off water of the rubber dam and the implementation process of the fuzzy PD controller, and then giving the actual control curve of constant current. Practice proves that the proposed control scheme is efficient and the system possesses good static, dynamic performance and certain robustness.
\end{abstract}

Keywords: industrial process control; constant current control; rubber dam; system of filling and draining off water; fuzzy $P D$

\section{Introduction}

Rubber dam is mainly composed of three parts rubber dam bag, civil engineering and drainage facilities, with the polymer composite materials industry's rapid development and the emergence of a new type of hydraulic structures in the 20th century late 1950s [1-3]. The advantage of Rubber dam have low cost, simple structure, save materials, short construction period, convenient operation, management and so on [4-7], and has been widely used in water conservancy, water electricity, water transportation, etc. After years of development, rubber dam technology is improving, and its corresponding supporting the automatic detection and control technology has been greatly developed and applied, particularly the most prominent drainage automatic control system in filling [8-12].

Flow is one of the three parameters in the industrial process control, and it must be accuracy controlled in the process of industrial production. Generally there are two kinds of traffic control methods about control flow. One is adopt AC inverter control the motor speed achieve a smooth output flow step less adjustment according to the quantitative, the other one is control the traffic of flow by regulating damper or valve opening. Frequency control mode not only save a lot of energy, but also can improve the service life of the valve, reduces system noise, thereby enhancing the reliability of the system compared with the other one [13-14].

As the complexity of the operating environment and the actual project filling drainage system structure design, this system is can not describe a precise mathematical model [15], 
multiple input multiple output, and strong coupling also show severe nonlinearities, large hysteresis, time variability and uncertainty [16]. Therefore, conventional PID control strategy or model-based control method can not achieve the purpose of precise control flow ,so Fuzzy Control Method [17-21]which Knowledge-based and does not depend on the model can solve this question provides a new way of thinking, fuzzy control first put the natural language into a computer accept algorithmic language, through simulation human thinking reasoning, expression of knowledge and experience in the use of uncertain fuzzy rules effectively controlled object deterministic control. Therefore it does not need to establish accurate mathematical model of the controlled object, only requires the site operator's experience and data summarized into a better control rules can achieve control purposes [22-25]. In view of the actual project operability and ease of implementation, in this project, we designed a fuzzy PD controller for rubber dam filled drainage control and adjust the constant flow based PC WinCC, in the actual filling rubber dam drainage achieved good control effect during operation, reached a constant flow sufficient drainage control purposes.

\section{System of Filling and Draining Off Water of the Rubber Dam}

Rubber dam filling rubber dam drainage system is the core of monitoring system, mainly consists of PC remote control systems, filling and emptying pumps, aqueducts road, inverter, electrical control devices, water level monitoring equipment, dam bag height and pressure detection devices, etc. According dam bag height, bag pressure and the dam on the downstream water level, through frequency equipment of pump motor start or stop and electric butterfly valve switch of aqueducts road control dam bag automatic filling or drainage, we have done filling or drainage system structure diagram in actual project as Figure 1.

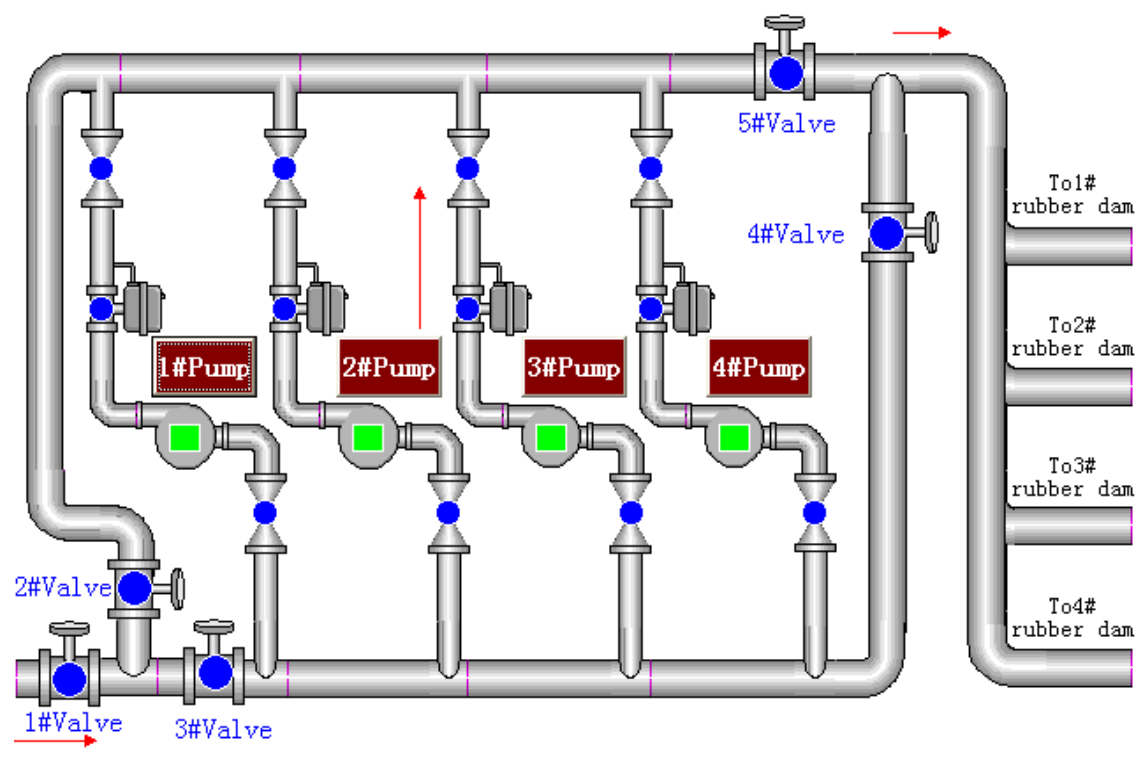

\section{Figure 1. System of Filling and Draining Off Water of the Rubber Dam}

This filling drainage system consists of four lengths of $100 \mathrm{~m}$, a height of $4 \mathrm{~m}$ rubber dam bag and four pumps constitute $75 \mathrm{Kw}$, four inventers control four water pumps. Only one filling process is the "machine charge". Opens the valve 1,3and valve 5, so that the formation of the corresponding water-filled path as Figure 1, the red arrow 
indicates the direction, then open the corresponding request dam bag inlet valve, and start the corresponding number of pumps to be filled with water on the dam bag regulation. Drainage process is divided into two ways, first, "self drainage", open the valve 1,2 and valve 5 or valve 1,3 and valves 4, making pipeline path, Rely on the dam bag or river pressure, so that the water does not pass through pump in the dam which outflow by themselves. This approach is relatively slow and can not control the speed of drainage. Another is the "machine drainage ", opens the valve 1,2 and valve 4 and corresponding dam bag inlet valve, start a corresponding number of pumps for drainage and regulate the dam bag.

The main problem of this filling drainage system is control of operating requirements under rubber dam, the total charge displacement within the allowable range in the rubber dam, adjust the inverter frequency reference after determining the open number of pumps, rubber dam bags inlet and outlet flow rate constant in the "machine filling" or " machine drainage " process, design a controller to adjust the pump speed by inverter based on PC, Dam bag of inlet and outlet flow rate stabilized at pre-set state in a short period of time, or track the trajectory of a set, meet certain dynamic performance and allowable static error requirements, satisfy, and the number of pump starts filling the dam can not be greater than the number of bags and other constraints.

\section{Fuzzy PD Controller Design}

We were filled dam drainage constant flow control tests on the rubber dam, according to the rubber dam upstream water level and flow changes. traffic affected by many factors, as The system itself (pipeline) design structure, dam bag with the charge, drainage highly variable pressure on the downstream water level, the number of charging and discharging dam bags and some outside interference, etc., system showed a high degree of nonlinearity and strong coupling, So no matter what kind of modeling method that can completely describe the dynamic characteristics, and the impact of the external environment of the process as well as characteristics of the object itself changes during the operation will bring uncertainty to the controlled object, so the traditional PID control is difficult to obtain satisfactory control effect, taking into account the traditional PID control applications in industrial processes breadth and fuzzy control technology features, combined with rubber dam filling drainage characteristics of the process, system performance requirements and control ease of implementation, we designed a fuzzy PD controller for rubber dam filled drainage control and regulate the constant flow.

\subsection{Incremental Digital PID Control Algorithm}

PID controller is a linear regulator; this regulator is composed of a given value of the system $r$ and actual output value $y$ and control deviation $e=r-y$ proportional, integral, differential, linear combination of the amount of control, continuous control system analog PID control law is:

$$
u(t)=K_{p}\left[e(t)+\frac{1}{T_{i}} \int_{0}^{t} e(\tau) d \tau+T_{d} \frac{d e(t)}{d t}\right]
$$

Here, $K_{p}$ scale factor, $T_{i}$ integral time constant, $T_{d}$ derivative time constant.

Corresponding transfer function is

$$
G(s)=\frac{U(s)}{E(s)}=K_{p}\left(1+\frac{1}{T_{i} s}+T_{d} s\right)
$$


In order to achieve computer-controlled production process variable must be discrete analog PID formula, when the actuator is needed is the incremental volume control (for example drive a stepper motor); incremental PID control should be used.

Formula (2) discrimination, according to Recursion can be obtained the principle:

$$
u(k)=K_{p} e(k)+K_{i} \sum_{j=0}^{k} e(j)+K_{d}[e(k)-e(k-1)]
$$

Formula (3) can be obtained incremental PID control formula:

$$
\begin{gathered}
\Delta u(k)=u(k)-u(k-1) \\
\Delta u(k)=K_{p}[e(k)-e(k-1)]+K_{i} e(k)+K_{d}[e(k)-2 e(k-1)+e(k-2)]
\end{gathered}
$$

Formula (5) can also be written as practical recursive type PID control formula:

$$
u(k)=u(k-1)+K_{p}[e(k)-e(k-1)]+K_{i} e(k)+K_{d}[e(k)-2 e(k-1)+e(k-2)]
$$

\subsection{Fuzzy Control Algorithm}

Fuzzy control, which based on fuzzy sets theory, fuzzy linguistic variables and fuzzy logic inference, is an important approach in computer intelligent control, its basic concept is first proposed by L. A. Zadeh who is a well-known professor from the University of California [25-32]. After decades of development, the fuzzy control theory and applied research have been obtained a major success. Compared with other modern control algorithms, the biggest advantage of fuzzy control is it does not require the precise mathematical model of the controlled object. This is what we select it in charge of the control system of filling and draining off water of the rubber dam. The basic principle of fuzzy control is shown in Figure 1 , it is a core part of the fuzzy controller, as shown in dotted line box. The control algorithm of fuzzy controller is implemented by the computer program. Implementation the process of fuzzy control algorithm is described as follows: The basic principle of fuzzy control is shown in Figure1; it is a core part of the fuzzy controller, as shown in dotted line box. The control algorithm of fuzzy controller is implemented by the computer program.

The implementation process of the fuzzy control algorithm is described as follows: Microcomputer get the exact value of the controlled volume by the interrupt sampling, then comparing with the given value to get the error signal E. Generally, electing the error signal E as an input of the fuzzy controller.

The exact amount of the error signal $\mathrm{E}$ becomes fuzzy quantity bying fuzzification. The fuzzy quantity of the error E could be represented by fuzzy language, and getting a subset of fuzzy

language set of the error E. ( $\vec{e}$ is a fuzzy vector). According to the synthetic rules of the fuzzy inference to fuzzy decision, getting the fuzzy control volume by $\vec{e}$ and fuzzy control rules $\vec{R}$ (fuzzy operator). $\vec{u}=\vec{e} \cdot \vec{R}$. 


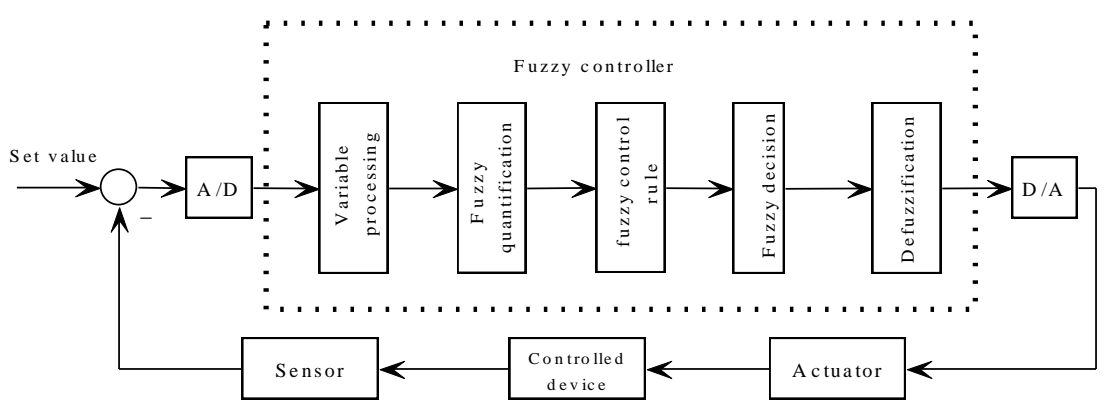

Figure 2. Fuzzy Control Principle Diagram

\subsection{Fuzzy PD Control Algorithm}

Fuzzy control is an intelligent control method, which based on fuzzy set theory, using the basic idea and theoretical of the fuzzy mathematics and combining fuzzy logic and fuzzy linguistic variables. However, the control accuracy of the fuzzy control is not high, it has been according to experts' experience, predetermine rules and membership functions of the

fuzzy controller, so to obtain good results is not easy. In the control process, the control strategy is determined in advance, so it does not have correction, self learning and adaptive ability. At present, having that the shortcomings of the traditional fuzzy control, many experts have done extensive research and improvement work, and it gradually formed a fuzzy control in various forms, and has the advantages of robustness and stability. At the same time, fuzzy control combined other control strategy has been appeared and made great development, such as fuzzy PID, fuzzy neural network, fuzzy variable structure sliding mode control, adaptive fuzzy neural network and so on. The fuzzy PD controllers have combined the advantages of both, and which have the advantages of fuzzy control of flexible and adaptable and the high precision of PID control. The following, introducing the implementation process of the fuzzy PD controller in details.

According to the operation needs, the system of filling and draining off water of the rubber dam can constitute a nonlinear system which has 4 inputs (speed) and 4 outputs (flow), In order to facilitate the research, we will approximate the system as 4 SISO (single input single output) systems. Now take one of them as an example, introduces the design process of fuzzy PD controller.

Considering the simple and rapid realization of the fuzzy control algorithm in in the actual projects, we used two-dimensional fuzzy controller structure. The error of flow and error change rate of the feedback system as the input of fuzzy controller, the control volume increment as the output of the controller. So we can get the structure chart of the system of filling and draining off water of the rubber dam based on fuzzy PD control as shown Figure 3. In the Figure $3, f_{s}$ is the set values of the flow, $f$ is the actual value of flow, $e\left(e=f_{s}-f\right)$ is the error of the flow, $e c$ is the change rate of flow error, $\Delta u$ is the control output and is the input frequency of the pump. The basic working process can be described as follows:

First, according to the membership function, the accurate quantity $e, e c$, become fuzzy quantity $E, E C$. Second getting the fuzzy control output $\Delta U$ by fuzzy inference according to the fuzzy control rule, and then getting accurate control quantity $\Delta u$ by deblurring. Last, getting the control signal $u$ by the standardized gain $K_{u}$. 


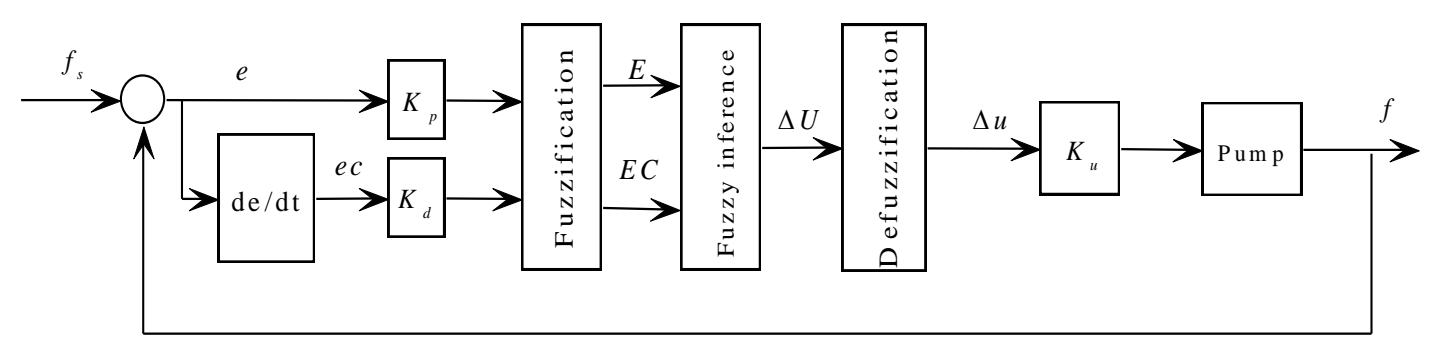

Figure 3. Fuzzy PD Controller Block Diagram

Until Establishment of membership function is the process of the input and output variables bying fuzzification. The fuzzy universe of the input variable $E, E C$ of the fuzzy PD controller is $\{-2000,2000\},\{-100,100\}$ in this project. The fuzzy universe of the output variable $\mathrm{U}$ is $\{-4000,4000\}$. The input, output of all fuzzy variables are described by the III linguistic variable fuzzy sets. They are NB, ZO, PB, and each expressed as negative big, zero and positive big. The fuzzy subset language variables of the error, error rate, incremental controls are defined as follows:
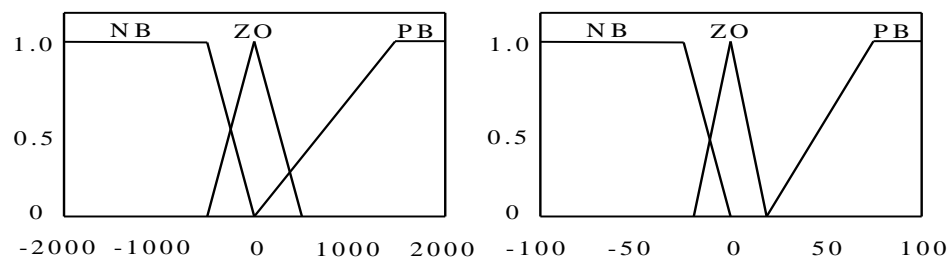

$\begin{array}{lll}\text { (a) Input variable } e & \text { (b) Input variable } e c\end{array}$

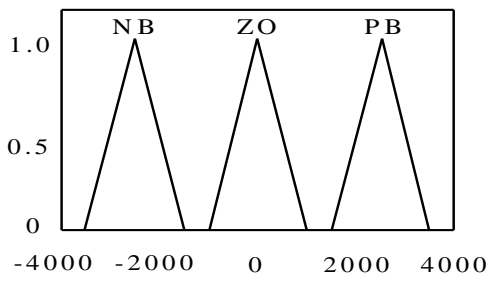

(c) Output variable $\square u$

Figure 4. Membership Function

Choosing different control rules has great effect in the fuzzy control. Therefore, the need for a reasonable selection of fuzzy control rules in the design, being selected rules as shown in

Table 1 .

Table 1. Fuzzy Control Rules

\begin{tabular}{|c|c|c|c|}
\hline u & NB & ZE & PB \\
\hline NB & NB & NB & PB \\
\hline ZE & NB & ZE & PB \\
\hline PB & NB & PB & PB \\
\hline
\end{tabular}


Through the control of output fuzzy reasoning is a fuzzy subset; it contains the amount of control information. But the physical object in practical control only to accept a certain control at a time. This requires the fuzzy decision (i.e., algorithm), to the fuzzy conversion become the exact amount. In this paper, adopt the weighted mean method (WMM), i.e. the membership function as the weighting function.

$$
\Delta u=\frac{\int \mu(\Delta U)(\Delta U)}{\int \mu(\Delta U)}
$$

\section{Implementation and Experiment of the Fuzzy PD}

This paper elaborates the basic principle of the fuzzy PD control and fuzzy PD control structure above. Then introduce the implementation of the fuzzy PD control system in the project. The actual control structure of the control system is as shown below. In the Figure 5, there are the calculations between of the actual flow and the set values, control conversion algorithm, Fuzzy PD control, Water pump frequency control, Electric valve control. And a series of processing units for detection of the upstream and downstream water level, dam bag vibration frequency, pressure inside the dam bag.

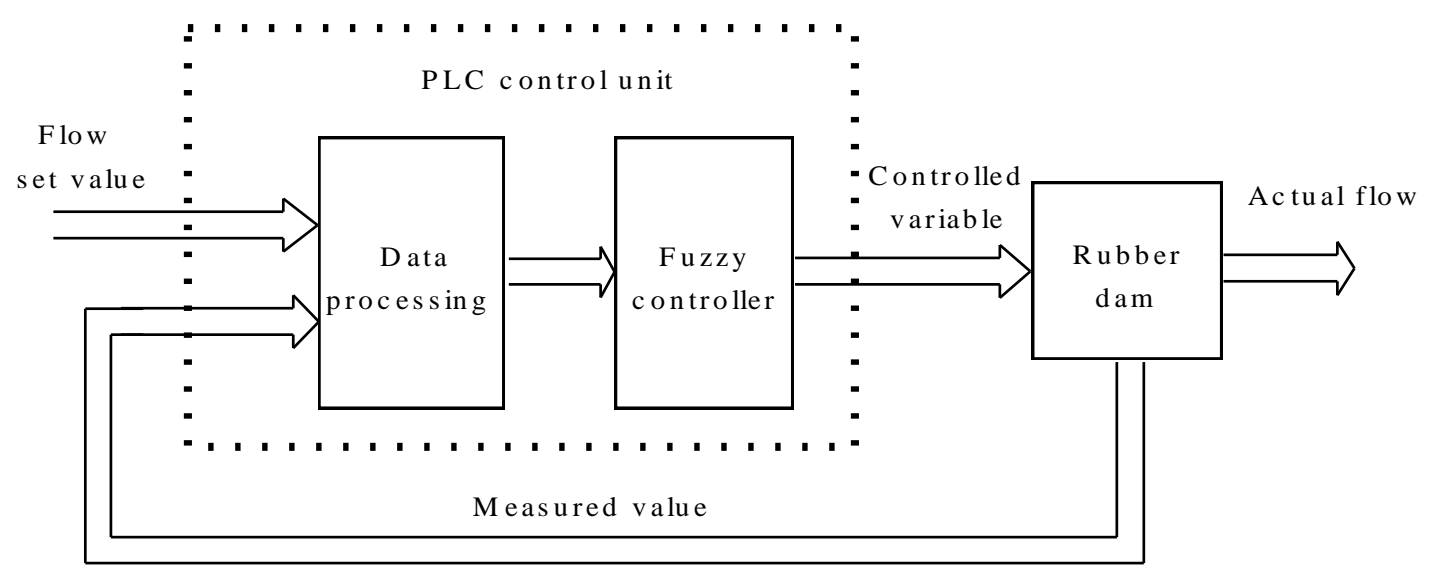

Figure 5. Control Structure of Filling and Draining Off Water of the Rubber Dam

The specific implementation steps of the fuzzy PD control in the PLC control program as follows:

For illustration, $f_{s}$ is the set values of the flow, $f$ is the actual value of flow, $e\left(e=f_{s}-f\right)$ is the error of the flow, ec is the change rate of flow error. Fuzzy PD controller of the system uses the PLC Direct look-up table method. And the main design steps of the direct look-up table method of fuzzy PD controller as following:

(1) Determine the fuzzy universe of the error, the error variation and the control outputs; (2) According to the rating of the fuzzy universe, combined with the proportionality factor, the actual range of the $e$, ec is averaged to $\mathrm{n}$ ranks. Make a rank corresponding to an element of fuzzy universe, so the exact value $e$ 、ec which been measured at some point could be quantified as the corresponding elements $X_{i} 、 Y_{j}$ in the fuzzy universe.

(3) According to the fuzzy control table, we could get the the output control quantity $U_{i j}$ of the $X_{i}$ 、 $Y_{j}$. 
(4) The control volume $U_{i j}$ multiplied by the scaling factor bying defuzzify is applied to the object.

The lower position machine is using Siemens S7-300PLC for data and information collection. The upper monitor is using WinCC configuration software to controlling and monitoring. The fuzzy PD controller described above is implemented by using ANSI C in the global script editor of WinCC. And in order to prevent computer in reasoning fuzzy processing required a lot of time, we are using look-up table method to realize fuzzy control. Finally, we carried out on-site commissioning. The experimental conditions as follows: Open two pumps, open four inlet valve of the rubber dam. That is realization the filling water experiment of the entire rubber dam.

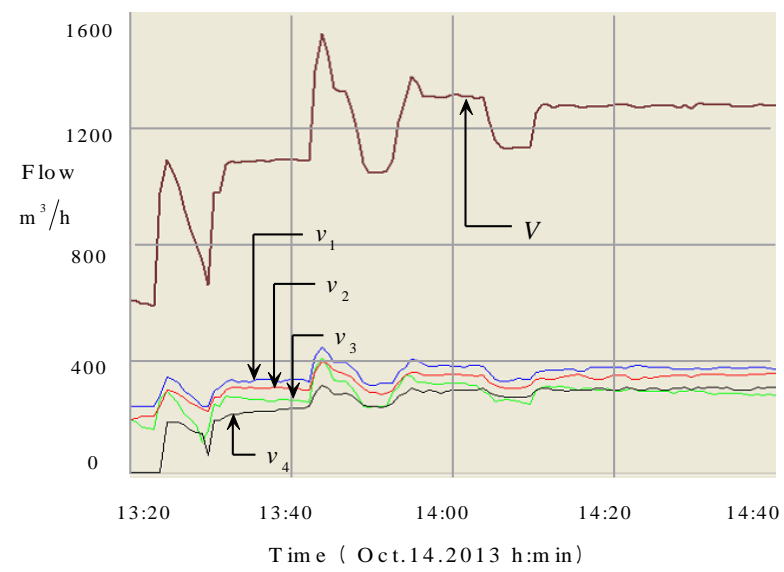

Figure 6. Actual Control Curve of Filling Water Process

From the above practical operation curve can be seen, when the total flushing flow set point is maintained, the actual total flow and the pipeline flow can better track the set value. Using fuzzy PD control method is effective to avoid the complexity of system of filling and draining off water of the rubber dam, and achieve the control purpose constant flow in water filling process.

\section{Conclusion}

For the complex practical control system of filling and draining off water of the rubber dam, a fuzzy PD controller is designed for the constant current control of filling and draining off water of the rubber dam, combining with the conventional PID algorithm which is widely used in industrial process control and the fuzzy control strategy without relying on accurate mathematical model, and achieved good control effect. Practice proves that the proposed control scheme is efficient and the system possesses good static, dynamic performance and certain robustness. But also after changing equipments the control method can be applied to the actual control of the analog temperature, liquid level and pressure and so on.

\section{References}

[1] Q. Liang and Y. F. Qu, "A texture-analysis-based design method for self-adaptive focus criterion function", Journal of Microscopy, vol. 246, no. 2, (2012), pp. 190-201 
[2] C. Yu, B. Wang, H. Zheng, X. Luo and M. Zhang, "Improved Tennen Grad function for microscopic coarse autofocusing", Optics and Precision Engineering, vol. 15, no. 5, (2007), pp. 784-789

[3] J. C. Hsieh and R. H. Plaut, "Vibrations of an inextensible cylindrical membrane inflated with liquid Journal of Flulds and Structures, vol. 3, (1989), pp. 151-163

[4] J. C. Hsieh and R. H. Plaut, "Frec vibrations of inflatable dams", Acta Mcehanica, vol. 85, (1990), pp. 207220.

[5] R. D. Parbery, "A continuous method of analysis for the inflatable dam", Proceedings of the Institution of Civil Engineers, Part 2[C]. [s.1.]: [s.n. ], vol. 61, (1976), pp. 725-736

[6] B. Gao, "Rubber Dam and Flood Denfenee", Proceeedings of the Second International Symposium on Flood Defenee", Beijing, China, vol. 009, no. 010, (2002), pp. 734-748

[7] R. H. Plaut, S. I. Liapis and D. P. Telionis, "When the levee inflates [J]", Civil Engineering, vol. 1, (1998), pp. 62-64.

[8] D. A. Conrad and D. P. Muldoon, "Design and application of a PC/PLC utility Rubber Dam control system", Instrument Society of America, vol. 6, (1995), pp. 351-362.

[9] X. Q. Zhang, P. W. M. Tam and W. Zheng, "Construction, operation, and maintenance of rubber dams [J]", Canadian Journal of Civil Engineering, vol. 29, (2002), pp. 409-420.

[10] G. V. Mysore and S. I. Liapis, "Dynamic Analysis of Single-anchor Inflatable Dams [J]", Journal of Sound and Vibration, (1998).

[11] A. M. Oliver, "A new rubber dam frame design--easier to use with a more secure fit [J]", Quintessence International, vol. 34, no. 06, (2003), pp. 203-212

[12] X. Q. Zhang, P. W. M. Tam and W. Zheng, "Construction, operation, and maintenance of rubber dams [J]", Canadian Journal of Civil Engineering, vol. 29, no. 03, (2002), pp. 408-420.

[13] Q. Zhang and Y. Diao, "Cascade rubber dams fall discharge calculation and analysis [J]", Canadian Journal of Civil Engineering, vol. 38, no. 08, (2011), pp. 957-962.

[14] Y.-H. Zhang, W.-J. Yan and G.-Z. Zhao, "Research on real-time soft measuring state parameters of rubber dam inflated by water [J]", Zhejiang Daxue Xuebao (Gongxue Ban), vol. 39, no. 09, (2005), pp. 1353-1357.

[15] J. Guo and Q. Chen, "An application of fuzzy control based on PLC in rubber dam monitoring system [C]", Proceedings - 2010 International Conference on System Science, Engineering Design and Manufacturing Informatization, vol. 02, (2010), pp. 266-269.

[16] M. R. Markus, C. A. Thompson and M. Ulukaya, "Enhanced artificial recharge utilizing inflatable rubber dams [C]", Proceedings of the 2nd International Symposium on Artificial Recharge of Ground Water, (1995), pp. 120-128.

[17] L. A. Zadeh, "Fuzzy sets [J]”, Information and Control, vol. 8, (1965), pp. 338-353

[18] C. C. Lee, "Fuzzy logic in control system fuzzy logic controller, Part I, II [J]", IEEE Trans. On Systems, Man, and Cybernetics, vol. 20, no. 2, (1990), pp. 404-435.

[19] D. P. Filev and R. R. Yager, "A generalized defuzzification method via BAD distributions [J]", Int. J. Intelligent Systems, vol. 6, no. 7, (1991), pp. 687-697.

[20] R. R. Yager and D. P. Filev, "SLIDE: a simple adatpive defuzzification method [J]", IEEE Trans. On Fuzzy Systems, vol. 1, no. 1, (1993), pp. 69-78.

[21] T. Jiang and Y. Li, "Multimode oriented polynomial transformation based defuzzification strategy and parameter learning procedure [J]”, IEEE Trans. On Systems, Man, and Cybernetics, vol. 27, no. 5, (1997), pp. 877-883.

[22] T. Takagi and M. Sugeno, "Fuzzy identification of systems and its applications to modeling and control [J]", IEEE Trans. On Systems, Man, and Cybernetics, vol. 15, no. 1, (1985), pp. 116-132.

[23] L. X. Wang, "Generating fuzzy rules by learning from examples [J]", IEEE Trans. On Systems, Man, and Cybernetics, USA, vol. 22, no. 6, (1992), pp. 1414-1427.

[24] L. X. Wang, "Fuzzy systems as universal approximators [A]", IEEE Int. Conf. Fuzzy Systems [C], San Diego, USA, (1992), pp. 1163-1170.

[25] X. J. Zeng and M. G. Signh, "Approximation theory of fuzzy systems-SISO case [J]”, IEEE Trans. On Fuzzy Systems, vol. 2, no. 2, (1994), pp. 162-17.

[26] B. Kosk, “ Fuzzy systems as universal approximators [J]”, IEEE Trans. on Computers, vol. 43, no. 11, (1994), pp. 1329-1333.

[27] H. Ying and T. Sugeno, "The fuzzy controllers using the simplified linear control rules are nonlinear variable gain controllers [J]", Automatica, vol. 34, no. 2, (1998), pp. 157-167.

[28] H. X. Li, "A comparative design and tuning for conventional fuzzy control [J]", IEEE Trans. on Systems, Man, and Cybernetics, vol. 27, no. 5, (1997), pp. 884-889.

[29] X. Liu, H. Zhang and T. Chai, "Structure analysis of three-dimensional fuzzy controller [J]", Acta Automatica Sinica, vol. 24, no. 2, (1998), pp. 230-235.

[30] E. Zhang, S. Shi and Z. Weng, "Comparative study of fuzzy control and PID control methods [J]", Journal of Shanghai Jiao-tong University, vol. 33, no. 4, (1999), pp. 501-503. 
International Journal of Hybrid Information Technology

Vol.8, No.1 (2015)

[31] D.-C. Quach, S. Huang, Q. Yin and C. Zhou, "An improved direct adaptive fuzzy controller for an uncertain dc motor speed control system”, TELKOMNIKA Indonesian Journal of Electrical Engineering, vol. 11, no. 2, (2013), pp. 1083-1092.

[32] P. Karuppanan and M. KamalaKanta, "Adaptive-fuzzy controller based shunt active filter for power line conditioners", TELKOMNIKA Indonesian Journal of Electrical Engineering, vol. 9, no. 2, (2011), pp. 203210. 